\title{
The Effectiveness of Car Scrapping Schemes in the Italian Market
}

\author{
Antonio A. Romano and Giuseppe Scandurra ${ }^{1}$
}

\begin{abstract}
The aim of this work is to examine the effectiveness of policies in support of the automotive industry that have taken place over the years and the link between car registration and consumer confidence. Firstly, through an intervention analysis, the series of total car registrations in Italy has been corrected for the effect of seasonality and incentives. Secondly, a Structural Vector Auto Regression model has been estimated in order to evaluate the effectiveness of the relationship between car registrations and consumers' confidence. The results show that policies in support of the automotive industry are useful if granted during an increasing economic trend. Otherwise they have no effect on sales of new vehicles.
\end{abstract}

\section{Introduction}

The recent economic turmoil, that in a first stage involved the international financial system, has expanded in the real sectors of the economy. In Italy, it has had a significant impact on economic activities resulting in a decrease in domestic production, rising unemployment and an increase of income support measures.

The reduction of the wealth of the country and the stagnation of consumption (particularly strong for durable goods) has prompted policy makers to adopt incentives in order to support some productive sectors characterized by strong vertical integration and with a large number of employed. In particular, the automotive sector has received major attention due to the decreasing trend in its production, which seemed to take the form of a structural crisis. The automotive industry represents a considerable part of the euro area economy, featuring strong inter linkages with other important industries along the value chain. Having been exposed to a weakening in demand, in particular for commercial vehicles, since the beginning of 2008, it has been among those hardest hit by the financial turmoil and the severe economic downturn.

\footnotetext{
${ }^{1}$ Dipartimento di Statistica e Matematica per la Ricerca Economica, Università di Napoli "Parthenope", via Medina, 40 - Napoli - 80133 - Italy; (antonio.romano) (giuseppe.scandurra)@uniparthenope.it
} 
Financial support to consumers is typically conditional on the scrapping of old cars and/or the purchase of new vehicles, which are generally less harmful to the environment. The government's incentives for the purchase of a new car granted to consumers $^{2}$ represent very widespread support for the automotive industry. They are not new in public policies to support the national economy and specific vehicle scrapping schemes have been implemented in many euro area countries in order to support production in the automotive industry.

Policy support has been thwarted in recent times by the financial crisis of 2009 which led to a marked worsening economic climate, the consequences of which still exist today. In a recent paper, Klier and Rubenstein (2011) find that regional policy has been a tacit implementation of a regional industrial policy in the USA, though not an explicitly adopted strategy.

The fiscal policies have focused on short-term measures to contain the impact that the financial market turmoil has had on the real economy. In Italy, the car scrapping schemes reduce the cost of a new car through a discount offered by the dealer and reimbursed to it by the government. The cost is partially compensated by $i$ ) an increase in tax revenues ii) a reduction in healthcare costs and maintenance, iii) a reduction of greenhouse emissions, iv) a reduction of the costs incurred by government to support the unemployed.

Obviously, car trading with government's incentives raises two issues:

a. The effectiveness of interventions;

b. Their ability to have real effects on domestic production.

Both issues are related to the economic cycle, and furthermore the business cycle is correlated with consumers' confidence, which can be considered as a proxy for propensity to purchase durable goods. In Italy, consumers' confidence is currently monitored by Institute for Studies and Economic Analyses (ISAE), and can be considered a leading indicator for the economic cycle. Therefore, if we consider the relationship between consumers' confidence and propensity to buy durable goods, it would be interesting to test whether the expected effects of car scrapping schemes are, or not, independent of the economic climate.

The aim of this paper is twofold: first, we assess the impact of car scrapping schemes in the vehicle registration; second, we study the relationship between the evolution of consumers' confidence and the (corrected for scrapping scheme effects using a intervention analysis) car registrations. This will make it possible to assess whether, and how, the consumers' confidence may have influenced the impact of car scrapping schemes. In the presence of a statistically significant relationship between this indicator and car registrations, we might consider the hypothesis that the choice of a historical period for car scrapping schemes is not

\footnotetext{
${ }^{2}$ In Italy the car trading with government's incentives are similar to the US program "Consumer Assistance to Recycle and Save"
} 
neutral with respect to effects expected from them. In particular, in this paper we test $i$ ) the presence of a causal relationship between the two variables and $i i$ ) the impact of a series of dynamic random noise in the system of variables. To the best of our knowledge, this kind of analysis has not been done before.

The paper is organized as follows. The next section describes the data and methodology used, while Section 3 reports the results. Section 4 studies the relationship between the variables through a simple Vector Autoregressive (VAR) model. In Section 5 we present a qualitative analysis that will determine the effectiveness of policies adopted in support of the automotive industry over the years. Section 6 concludes.

\section{Data and method}

The data are the monthly time series from January, 1993 to August, 2010 of Italian's new car registrations (source: Italian Minister of Transport) and consumers' confidence (source: Institute for Studies and Economic Analyses). The first step is to identify the impact of car scrapping schemes in the time series of car registrations, applying an intervention analysis.

The intervention analysis was carried out with the popular method proposed by Box and Tiao (1975). In this approach, the interventions are represented in the model via a dummy or indicator variable It (Montgomery et al., 1990). For example, if an intervention at time $\mathrm{T}$ is deemed to have an abrupt, permanent effect, then It would be set to 0 for $\mathrm{t}\langle\mathrm{T}$ and 1 for $\mathrm{t}\rangle=\mathrm{T}$. If the intervention is thought to have an abrupt but temporary impact, then It will take a value of 0 prior to the intervention, a value of 1 at time $T$, and a value of 0 thereafter. Different distinct functions of It correspond to different types of intervention (Box and Tiao, 1975). Should more than one intervention impinge on a time series, then other dummies are introduced.

The basic intervention model can be written as:

$$
y_{t}=f\left(I_{t}\right)+N_{t}
$$

where $y_{t}$ is the car registration series, $f\left(I_{t}\right)$ represents the effects of the intervention events in terms of some deterministic input series and $N_{t}$ denotes the noise component. The noise component is the autoregressive integrated moving average (ARIMA) model. The ARIMA model can be expressed as:

$$
N_{t}=\frac{\theta(B)}{\varphi(B)(1-B)^{d}} \varepsilon_{t}
$$


where $B$ is the backshift operator, $\varphi(B)$ is the autoregressive operator represented by polynomials of the back shift operator, $\theta(B)$ is the moving average operator represented by polynomials of the back shift operator, $d$ is the order of regular difference, and $\varepsilon_{\mathrm{t}}$ is the random error, assumed to have a zero-mean, constant variance and to be serially independent.

The intervention effect is modeled as

$$
f\left(I_{t}\right)=\omega I_{t}
$$

in which $\omega$ is the impact of the interruption on the series.

Intervention analysis starts by identifying a suitable ARIMA component for the time series. The Box-Jenkins (Box and Jenkins, 1976) procedure is used to identify the model. There are three stages in the Box-Jenkins approach: identification stage, estimation stage, and diagnostic stage. At the identification stage, we have to determine the order of non-stationarity and the order of the autoregressive and moving average components $(\mathrm{p}, \mathrm{d}, \mathrm{q})$. In order to determine whether the series is stationary or not, we analyze the graph of the autocorrelation function (ACF). Then, the form of the plots of the ACF and partial autocorrelation function (PACF) constructed over several time lags suggests which of the autoregressive (AR) terms and/or moving average (MA) terms should be included in the $N_{t}$ component.

At the estimation stage, the coefficients of the model are estimated using maximum likelihood estimation. The log-likelihood function uses the covariance matrix of the vector calculated from equation (2.2), and the significance of the model are tested as well. At the diagnostic stage the residuals of the model are tested as to whether or not they are white noise, using the Box-Pierce Q statistic (Box and Pierce, 1970).

\section{Results}

In order to identify the suitable ARIMA model, firstly we have removed the seasonal component, running the Tramo - Seat procedure (Gómez and Maravall, 1996). The seasonally adjusted car registration series (Figure 1) has been analyzed in order to assess the impact of car scrapping schemes. Considering the numerous incentives, we have iteratively applied the intervention analysis (Tsay, 1986; Tiao, 1985; Box et al., 1994; Enders, 2004). We briefly describe the steps:

a. Identification of the most appropriate ARIMA model for the first section of the vehicle registration series, examining the sample autocorrelations plot and performing the model diagnostics. For example, the first section starts 
from the first observation and stops when the first incentive is concluded (time span: from 01/1993 to 09/1997);

b. Having identified a suitable ARIMA component $N_{t}$, the deterministic component $f\left(I_{t}\right)$ is added to the model. In the first step, we examine the portion of the time series that includes the first car scrapping scheme (from January, 1997 to September, 1997), running from the start of the series at 01/1993 up to just before the second potential intervention (October, 1997). The following step function has been included in the model estimation:

$$
f\left(I_{t}\right)= \begin{cases}1, & \text { January, } 1997 \leq I_{t} \leq \text { September, } 1997 \\ 0, & \text { otherwise }\end{cases}
$$

(we use an AutoRegressive Moving Average model with eXogenous variable - ARMAX - procedure, based on maximum likelihood);

c. In order to identify the delay between the start of the policy intervention and when it shows the effects on the car registration series, we firstly estimate various ARIMA models including the exogenous variable (incentives) at different lag length (from 0 to 2). We select the appropriate lag length by the Akaike Information Criterion (AIC) (Akaike, 1973);

d. If the impact of this first intervention is statistically significant, we subtract the estimated effect of incentive from the observed car registrations between 01/1997 and 09/2007; the new time series does not take into consideration the first car scrapping scheme;

e. We now move on to the second intervention. We consider that part of the time series that includes the second car scrapping scheme, running from $1 / 1993$ to just before the onset of the third intervention (July, 2002). We identify the more suitable ARIMA model for this series and add a new deterministic component and estimate it at different lags:

$$
f\left(I_{t}\right)=\left\{\begin{array}{l}
1, \text { October, } 1997 \leq I_{t} \leq \text { July, } 1998 \\
0, \text { otherwise }
\end{array}\right.
$$

f. If the impact of this second intervention is statistically significant, we subtract the estimated effect of this incentive from the observed car registrations between 10/1997 and 07/1998;

g. Steps (a) to (f) are repeated until all further car scrapping schemes are analyzed (Table 1$)^{3}$.

At the end of the adjustment procedure, the new (corrected) data series does not include the impact of the car scrapping schemes.

\footnotetext{
${ }^{3} \mathrm{We}$ do not report the ACF and PACF useful to determine the ARIMA model. They are available upon request to the Authors.
} 
Table 2 shows the parameter estimates of the incentives that followed.

Table 1: Summary of the Italian car scrapping schemes.

\begin{tabular}{|c|c|}
\hline $\begin{array}{c}\text { Car scrapping } \\
\text { schemes }\end{array}$ & Time span \\
\hline 1 & From January, 1997 to September, 1997 \\
\hline 2 & From October, 1997 to July, 1998 \\
\hline 3 & From July, 2002 to December, 2002 \\
\hline 4 & from October, 2006 to December, 2008 \\
\hline 5 & From February, 2009 to December, 2009 \\
\hline
\end{tabular}

Table 2: Data Generating processes and estimated impact of incentives $\left(I_{t}\right)$ for the series of car registrations.

\begin{tabular}{|c|c|c|c|c|c|}
\hline & $\begin{array}{c}1^{\text {st }} \\
\text { incentive }\end{array}$ & $\begin{array}{c}2^{\text {nd }} \\
\text { incentive }\end{array}$ & $\begin{array}{c}3^{\text {rd }} \\
\text { incentive }\end{array}$ & $\begin{array}{c}4^{\text {th }} \\
\text { incentive }\end{array}$ & $\begin{array}{c}5^{\text {th }} \\
\text { incentive }\end{array}$ \\
\hline $\begin{array}{c}\text { Time span of } \\
\text { the car } \\
\begin{array}{c}\text { registration } \\
\text { series }\end{array}\end{array}$ & $\begin{array}{c}01 / 1993- \\
09 / 1997\end{array}$ & $\begin{array}{c}01 / 1993- \\
07 / 2002\end{array}$ & $\begin{array}{c}01 / 1993- \\
10 / 2006\end{array}$ & $\begin{array}{c}01 / 1993- \\
01 / 2009\end{array}$ & $\begin{array}{c}01 / 1993- \\
08 / 2010\end{array}$ \\
\hline $\begin{array}{c}\text { Time span of } \\
\text { scrapping } \\
\text { schemes }\end{array}$ & $01 / 1997-$ & $10 / 1997-$ & $07 / 2002-$ & $10 / 2006-$ & $02 / 2009-$ \\
$12 / 2002$ & $12 / 2008$ & $12 / 2009$ \\
\hline Observations & 55 & 107 & 143 & 191 & 211 \\
\hline $\begin{array}{c}\text { ARIMA } \\
\text { model }\end{array}$ & $(1,0,0)$ & $(1,1,0)$ & $(1,1,0)$ & $(1,1,0)$ & $(1,1,0)$ \\
\hline Lags of $I_{t}$ & 2 & 1 & 0 & 0 & 0 \\
\hline$I_{t}$ & $26152.2 *$ & -2910.98 & 2376.51 & -1427.27 & $4652.86 *$ \\
& $* *$ & & & & $*$ \\
\hline
\end{tabular}

Significance levels: ***: 1\%; **: 5\%; *: $10 \%$.

Only the first and the last car scrapping schemes are statistically significant. In particular, the first has increased car demand by 26152 additional units per month representing $7.9 \%$ above expectation. We now consider the last intervention, from February, 2009 to December, 2009. In this period Italy, like most of the world economies, passed through financial turmoil. In this period the car scrapping scheme is significant but its impact is smaller compared to the first scrapping scheme. Only 4653 additional cars are sold in this period and represents an increase of just over $2 \%$ from expectation should this intervention not have taken place. Another feature of the last intervention was to have taken effect without delays. Other car scrapping schemes do not have a significant impact on car registrations. At the macroeconomic level, there is some evidence that rising car 
registrations had an upward impact on private consumption in the first half of 2009 in the euro area as a whole.

Figure 1 shows the number of registrations after eliminating incentives. As we can see from the figure, there is a jump in the average level of car registrations that occurred in conjunction with the first car scrapping scheme. This average has remained constant up to midway 1990. This time there have been interventions that do not seem to have had significant effects. Among other things, you cannot exclude the theoretical possibility that in the absence of interventions the results are not significant, the downward trend in sales would have been more evident than that observed between 2001 and 2005. Finally, the apparent collapse of the observed registrations in 2008 could be attributed to the beginning of the recent financial crisis perceived by Italian families who have apparently responded by postponing purchases of economic importance. Finally, the intervention in 2009 had an impact in the short run that is reabsorbed within a few months.

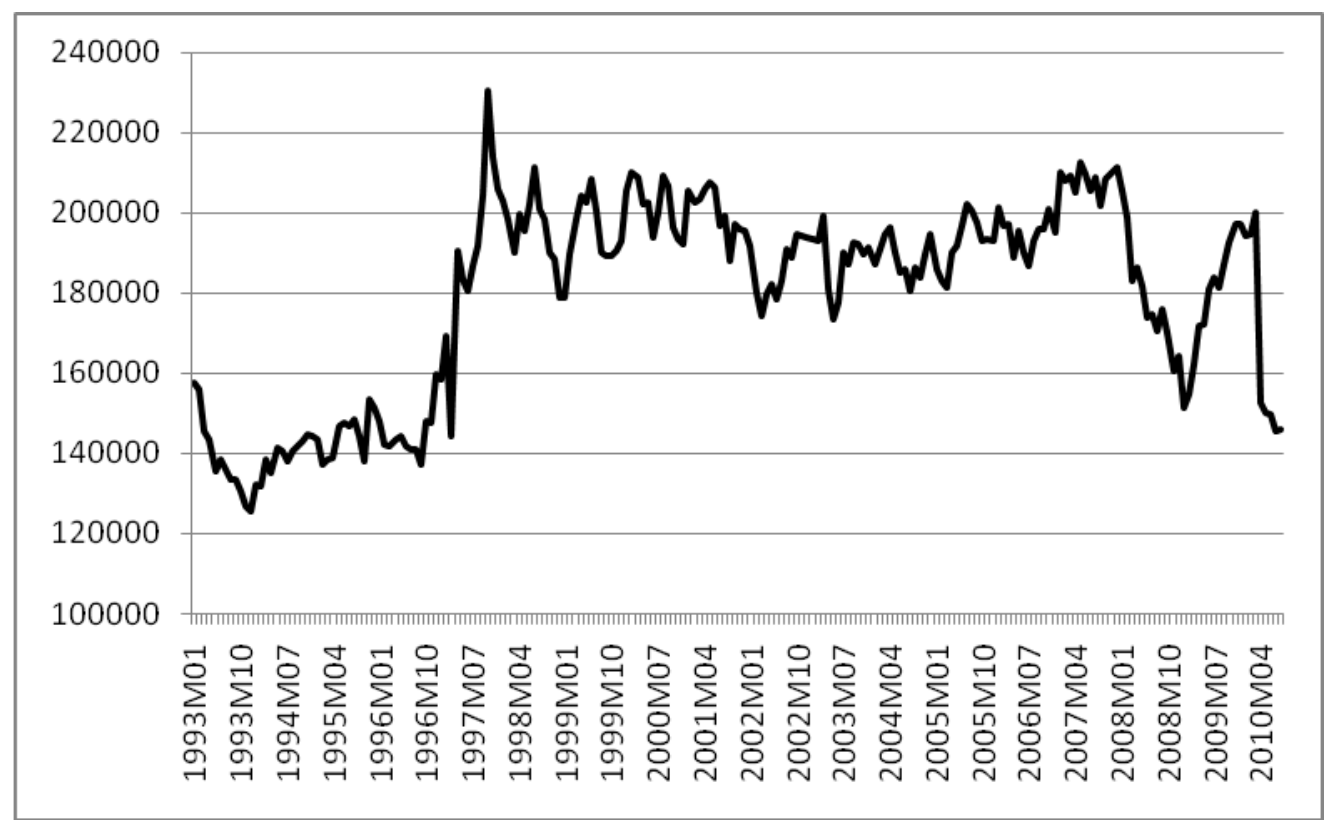

Figure 1: Car registrations without strapping incentives.

There are, of course, other possible explanations other than the impact of interventions on registrations that have taken place over time. The idea is that the economic impact of an intervention is not entirely independent from the time at which this procedure is in place. In other words, there may be a relationship between the impact of the car scrapping scheme and the business climate. On the latter case we investigate in the next section. 


\section{Car registrations and consumers' confidence}

Consumers' confidence that, in Italy, is currently monitored by ISAE and it is considered a leading indicator of the economic cycle. Therefore, if we consider the relationship between consumers' confidence and propensity to buy durable goods, we have to test if there is a statistical relationship between the estimated impact of the vehicle scrapping schemes and consumers' confidence. For this reason, we want to analyze the relationship between consumers' confidence (seasonally adjusted and corrected for outliers) and car registrations in Italy (seasonally adjusted and corrected for effect of incentives).

The analysis will attempt to assess the causal link between consumers' confidence and the impact of incentives. Empirical evidence about the presence of causal relationship between the two variables suggests that the effect of an intervention is affected by the historical time of its application, that is, from its position with respect to the business cycle. According to economists, if private households reduced their savings or increased their borrowing to finance their new car purchases, a negative impact on future overall private consumption growth can be expected to the extent that private households need to reduce their borrowing and increase savings again.

We test if an equilibrium relationship between consumers' confidence and car registrations can be found. To formalize this, we estimate the following long run equation:

$$
T O_{t}=b_{0}+b_{1} C O_{t}+e_{t},
$$

where $T O$ is the corrected car registration series, $C O$ is consumers' confidence and $e_{t}$ are the regression residuals.

The first step in examining trends in a set of variables is to test for the presence of a stochastic trend in the autoregressive representation of each individual series with an Augmented Dickey Fuller (ADF) test (Dickey and Fuller, 1979). If we are not able to reject the null hypothesis that there is a unit root, we run the $\mathrm{ADF}$ on the first differences of the original time series. In this step, we should be already able to reject the null hypothesis (presence of a unit root) in order to be able to conclude that the original time series are I(1) (Table 3). Since a stochastic trend has been confirmed for consumers' confidence and car registrations, we now analyze the presence of shared stochastic trends among these series using the cointegration procedure proposed by Engle and Granger $(1987)^{4}$. Therefore, we estimate the long-run relationships (4.1) and save regression residuals. Then we test whether the residuals are stationary using again the

\footnotetext{
${ }^{4} \mathrm{We}$ also test the cointegration hypothesis with the test procedure proposed by Johansen and Juselius (1990) that has confirmed the previous result.
} 
standard ADF. If we are able to reject the null hypothesis about the unit root, we can conclude that the variables in (4.1) are cointegrated of order $C I(1,1)$.

Table 3: Augmented Dickey Fuller (ADF) test for consumers' confidence and car registrations.

\begin{tabular}{|c|c|c|}
\hline & ADF & $\mathrm{P}-$ value \\
\hline $\begin{array}{c}\text { Consumers } \\
\text { confidence }\end{array}$ & -2.28 & 0.18 \\
\hline Car registrations & -2.17 & 0.22 \\
\hline
\end{tabular}

Table 4: Engle - Granger (1987) cointegration test (Augmented Dickey Fuller test on regression residual).

\begin{tabular}{|l|c|c|}
\hline & ADF & P-value \\
\hline $\begin{array}{l}\text { Regression } \\
\text { residuals }\end{array}$ & -2.44 & 0.30 \\
\hline
\end{tabular}

However, the ADF test statistic on the residuals of the long run equation (4.1) fails to reject the null hypothesis of no cointegration (Table 4). There is a lack of a long-run equilibrium relationship between variables. Therefore, we estimate a Vector Autoregressive (VAR) model, differencing the series of car registrations (DTO) and consumers' confidence (DCO) in order to eliminate the stochastic trend. The VAR approach is a methodology frequently used to analyze the dynamic impacts of different types of random disturbances on the variables in the model (Ferreira et al., 2005). However, the reduced form of VAR does not consider the structural relationship among the variables. Therefore, a Structural VAR (SVAR) can be used to predict the effects of specific policy actions or of important changes in the economy (Narayan et al., 2008). A simple Granger causality test (Granger, 1969) suggests the restrictions that we have to impose on SVAR model (Table 5).

Table 5: Granger causality test.

\begin{tabular}{|c|c|c|}
\hline Null hypothesis: & F - statistic & P - value \\
\hline $\begin{array}{c}\text { Car registrations do not Granger - cause } \\
\text { consumers' confidence }\end{array}$ & 0.10940 & 0.7412 \\
\hline $\begin{array}{c}\text { Consumers' confidence does not Granger - } \\
\text { cause car registrations }\end{array}$ & 3.20075 & 0.0751 \\
\hline
\end{tabular}


From Table 4, Granger causality tests indicate that the effects of DCL on DTO are significant at $10 \%$, whereas the effects of car registrations on consumers' confidence are not significant at conventional levels. Thus, causality is unidirectional: consumers' confidence affects car registrations but not the reverse. The effects of an intervention are not evident during an unfavorable economic climate. For the SVAR, a lag length of 8 is selected according to AIC. The constraints are based on the Granger causality tests. We assume that car registrations do not affect consumers' confidence in the short-run, meaning that car registrations increases do not alter consumers' confidence.

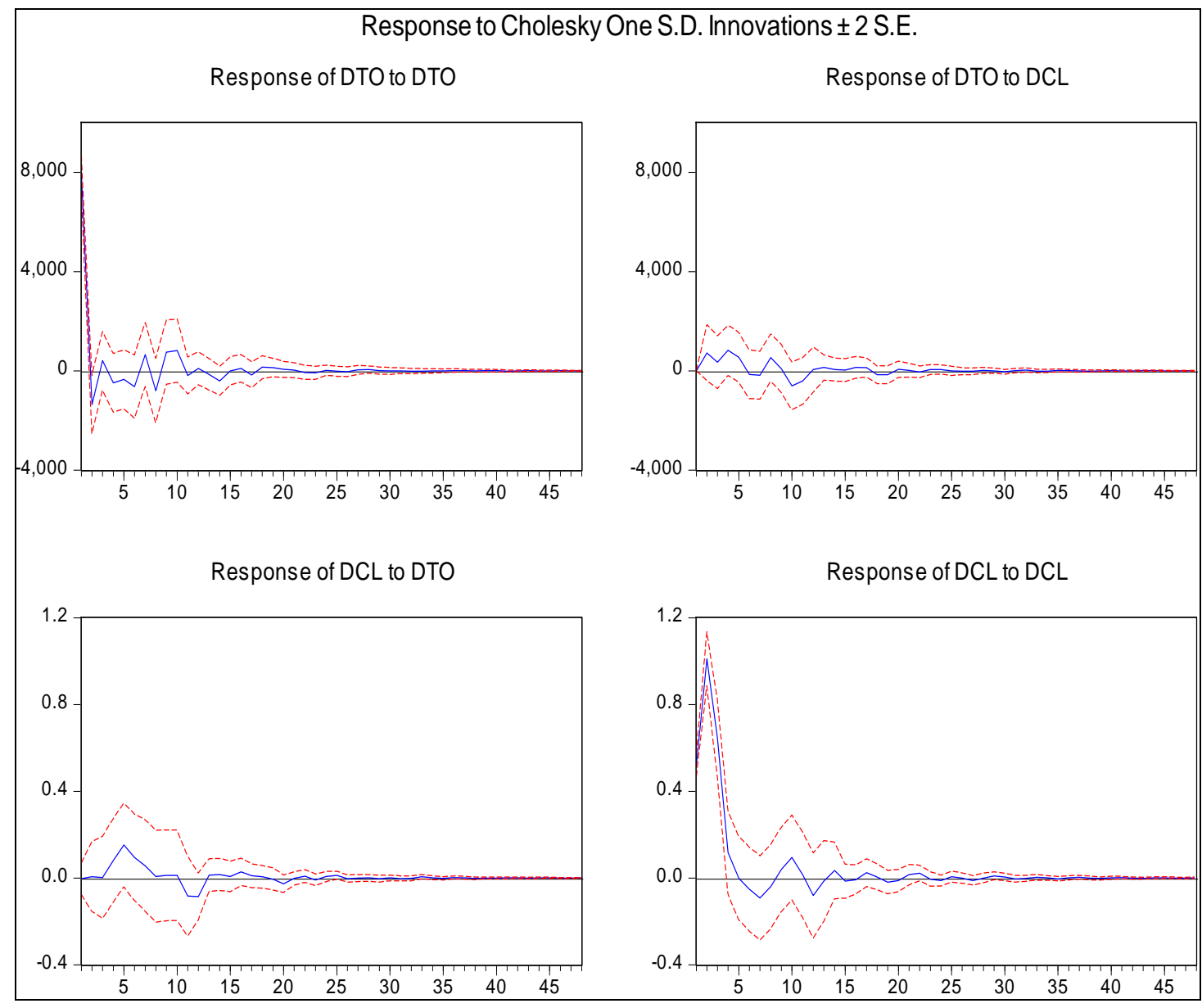

Figure 2: Impulse Response Functions.

In order to know the response of one variable to an impulse in another variable in a system is useful to investigate the impulse response relationship between the two variables. An impulse response function (IRF) traces the effect of a one - time shock to one of the innovations on current and future values of the endogenous variables (e.g. Robalo and Salvado, 2008). Plotting the IRF is a practical way to 
visually represent the behaviour of DCL and DTO series in response to various shocks 5 .

Figure 2 reports the IRF and the 95\% bootstrap confidence intervals for the two variables ${ }^{6}$. A shock in consumers' confidence causes an immediate increase in car registrations. These changes are temporary. The car registrations converge to a long - run equilibrium after about 12 months. When a shock occurs in car registrations, consumers' confidence does not have an immediate increase. It is clear only after 3 months and the series converge after about 14 months.

Table 6: Variance decomposition.

\begin{tabular}{|c|c|c|}
\hline Period & $\begin{array}{c}\text { Variance } \\
\text { decomposition of } \\
\text { car registrations }\end{array}$ & $\begin{array}{c}\text { Variance } \\
\text { decomposition of } \\
\text { consumers' confidence }\end{array}$ \\
\hline 1 & 0.000000 & 0.007413 \\
\hline 2 & 0.000635 & 0.857941 \\
\hline 3 & 0.004217 & 1.008114 \\
\hline 4 & 0.396109 & 2.086407 \\
\hline 5 & 2.157289 & 2.560805 \\
\hline 6 & 3.225557 & 2.596899 \\
\hline 12 & 5.007819 & 3.665365 \\
\hline 24 & 5.149495 & 3.761094 \\
\hline 48 & 5.152286 & 3.769294 \\
\hline
\end{tabular}

Furthermore, the variance decomposition (Table 6) separates the variation in an endogenous variable into the component shocks to the VAR. Thus, the variance decomposition provides information about the relative importance of each random

\footnotetext{
${ }^{5}$ It is an essential tool in empirical causal analysis and policy effectiveness analysis. A lot of books explain how IRF is calculated. See, e.g., Enders (2004); Kirchgässner and Wolters (2007); Luktepohl (2005); Luktepohl and Kratzig (2004).

${ }^{6}$ Sampling is performed from the fitted residuals of the original VAR. We carry out a set of repetitions where for each repetition a set of observations is randomly drawn without replacement from the original data. The set of observations will be of the same size as the original data. For each repetition, we recalculate the IRF for the randomly drawn data. When all the 999 repetitions are complete, the procedure shows the quantiles 0,025 and 0,975 with point estimates.
} 
innovation in affecting the variables in the VAR. It gives us the ratio changes over time in one of the variables due to a shock of the variable (car registrations $\rightarrow$ confidence) compared with a shock of another covariant variable (confidence $\rightarrow$ registrations).

Table 5 shows the results of variance decomposition. It shows that a shock in car registration explains only a small part of the variance in confidence, however, only within a limited period of time (up to a year). The successive increments are very small. Instead, a shock in consumers' confidence accounts for a relatively higher part of the variance in registrations, in the same timeframe. In any case, the increases in the long term are very low and, over a horizon of 48 months, virtually null. These results suggest that the policy in support of registrations, if it ever has had some effect, does not generate any particular impact on the climate of consumer confidence, which is reasonably affected by the general economic and political framework on which the impact of car sales has little effect.

\section{A qualitative analysis}

The results provide evidence for the presence of a causal relationship between sales of new cars in Italy and consumers' confidence. We want to explore, now, if the causal relationship found could be used to better understand the dynamic of the effectiveness of car scrapping schemes that have been promoted by policy makers several times, but which do not have the same effect. In fact, while some incentives have had a significant effect on car registrations (Table 2), for other ones there was no empirical evidence of a positive impact on vehicle demand.

The impact of car scrapping incentives shows heterogeneity of behavior that is worthwhile to analyze with respect to the time of application for intervention, using a qualitative graphical analysis.

We replace the series of consumers' confidence and car registrations by their time partial averages. In particular, as regards consumers' confidence, the points at which the derivatives of the curve vanish are characteristic of a change in the trend of the averages (local maximum or local minimum). From these identified points, the curve of consumers' confidence has been replaced by the average within the period:

$$
\overline{D C L}_{j}=\frac{1}{n_{0}} \sum_{i=1}^{n_{0}} D C L_{i, j}
$$

where $D C L_{i, \mathrm{j}}$ is the index of consumer's confidence for each time span $j$ (between change in the trend) and $i\left(i=1, \ldots, n_{0}\right)$ are the observations. In Figure 3 we report the curve of the partial averages versus time. 
For car registrations, we replace the original series with its average of the time span $p$ delimited by the incentives (Figure 4):

$$
\overline{D T O}_{p}=\frac{1}{k_{0}} \sum_{k=1}^{k_{0}} D T O_{k p p}
$$

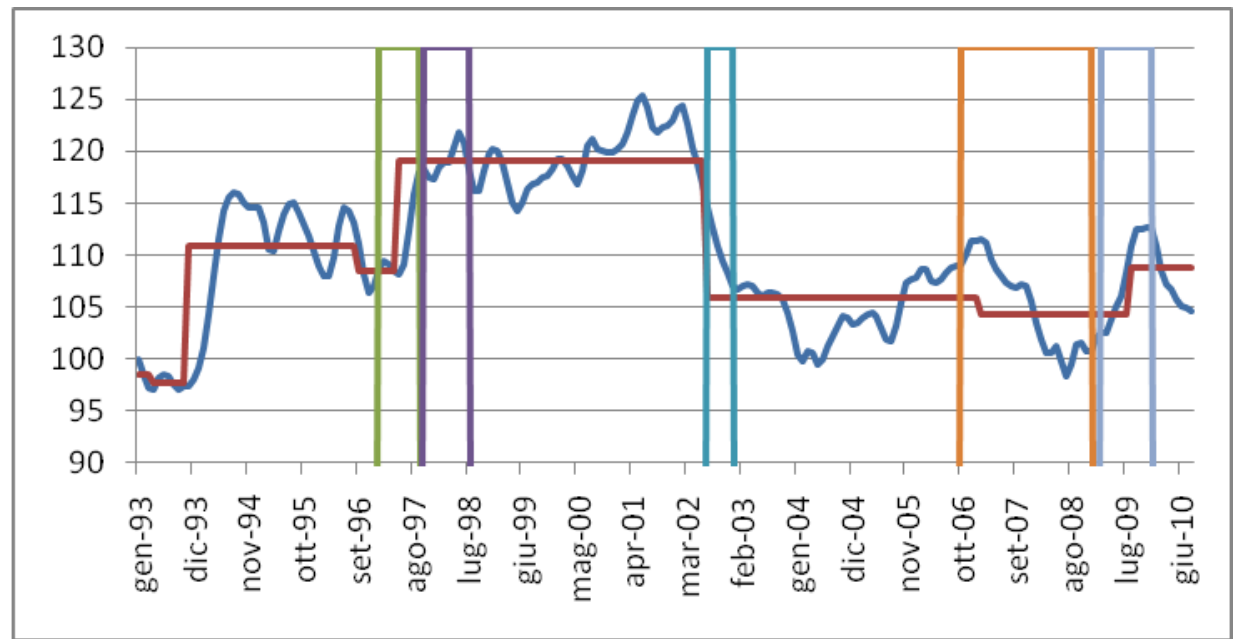

Figure 3: Consumers' confidence, partial average and car scrapping incentives (vertical lines).

A comparison between the two curves indicates that the positive effect of incentives follows the growth in consumers' confidence. Both quantitative and quantitative analysis suggests that car scrapping schemes are not sufficient to prevail upon families to replace an old car.

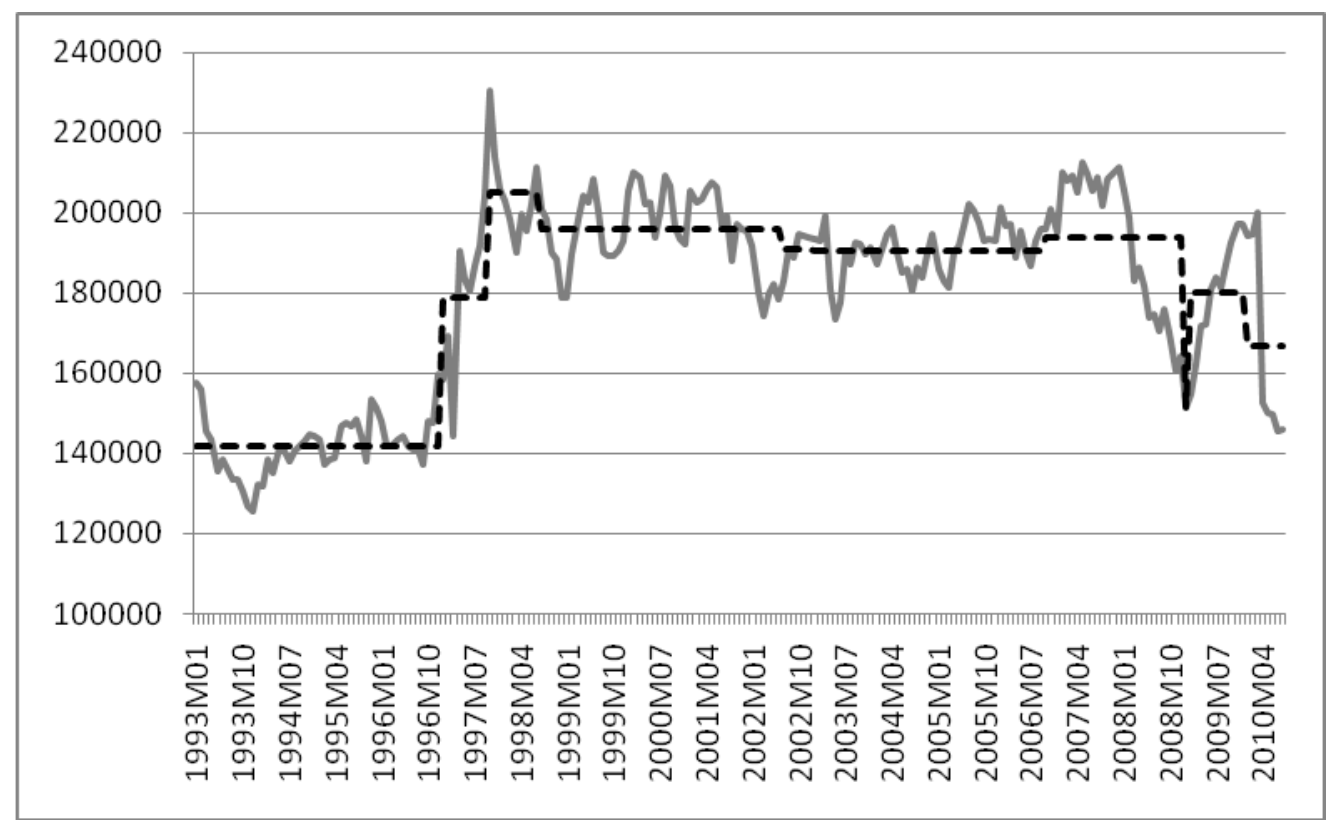

Figure 4: Car registrations (solid line) and partial averages (dashed line). January, 1993 - August, 2010. 
There is to be taken into account the effect due to the amount of interventions and their distribution over time: as these programmes are temporary and consist mostly in a shift of purchases from the future to the present, the surge in sales is likely to be reversed after the schemes end. Evidence on the timing and the magnitude of this "payback effect" varies but suggests that over the short term, car sales may be temporarily depressed by the termination of scrapping programmes in many countries (ECB, 2009).

\section{Summary and conclusions}

The paper investigates the effectiveness of the car scrapping schemes and their link with consumers' confidence which, as is known, is an indicator that summarizes consumer perceptions about economic growth. Firstly, we analyze the impact of car scrapping schemes in a series of car registrations, identifying some key features. Secondly, we investigate the causal relationship between the corrected car registration series and consumers' confidence and qualitatively analyze the dynamic of the incentives.

The results showed that the incentives that have been offered several times by the policy makers in Italy have not always had a significant impact on registrations of new cars. Only two schemes had a significant impact on vehicle registrations. The vehicle scrapping schemes in Italy appear to have provided significant support to car production in the 1997 and 2009. A substantial weakening of car demand has been observed after the first schemes in 1997. To the extent that the vehicle scrapping premium has lowered the average age of the car fleet, an adverse effect on new car demand will also prevail in the medium term. In fact, the other schemes do not have an impact on vehicle registrations, except that adopted in 2009. However, also in this case, a negative impact on demand for new cars has been observed once the measures have been phased out. The car scrapping schemes lower the prices of current as opposed to future car purchases and thereby lead to a frontloading of private car purchases. The more car purchases have been brought forward into 1997 and 2009 as a result of the measures, the stronger this negative impact was.

The causal relationship between consumers' confidence and car registrations confirms that it is useful to provide confidence to the analysis of trends in registrations. The adoption of new car scrapping schemes, must necessarily take into account consumers' confidence. Only during an increasing business cycle do they have a significant impact and can help the economic system. Vehicle scrapping schemes adopted in a recession period in consumers' confidence do not make any significant changes to car registrations. The period for new incentives should therefore be done in phases characterized by a period of expansion of consumers' confidence indicator. 
In a forthcoming work we analyze the effect of incentives for brand on the Italian market.

\section{Acknowledgements}

The authors wish to thank two anonymous referee and the editors for very useful comments and suggestions. The usual disclaimer applies.

\section{References}

[1] Akaike, H. (1973): Maximum likelihood identification of Gaussian autoregressive moving-average models. Biometrika, 60, 255-266.

[2] Box, G.E. and Tiao G.C. (1975): Intervention analysis with applications to economic and environmental problems. Journal of the American Statistical Association, 70, 70 - 79.

[3] Box, G.E. and Jenkins G.M. (1976): Time Series Analysis: Forecasting and Control, Revised Edition, Oakland, CA: Holden-Day.

[4] Box, G.E. and Pierce D.A. (1970): Distribution of residual autocorrelations in autoregressive integrated moving average time series models. Journal of the American Statistical Association, 65, 1509-1526.

[5] Box, G.E., Jenkins G.M., and Reinsel G.C. (1994): Time Series Analysis, Forecasting and Control ( $3^{\text {th }}$ eds). Englewood Cliffs: Prentice Hall.

[6] Dickey, D.A. and Fuller W.A. (1979): Distribution of the estimators for autoregressive time series with a unit root. Journal of the American Statistical Association, 74, 427-431.

[7] ECB (European Central Bank) (2009): Monthly Bulletin, October.

[8] Enders, W. (2004): Applied Econometric Time series. Wiley Series in Probability ad Statistics. Wiley.

[9] Engle, R.F. and Granger C.W. (1987): Cointegration and error correction: Representation, estimation and testing. Econometrica, 55, 251-276

[10] Ferreira, P., Soares I., and Araujo M. (2005): Liberalisation, consumption heterogeneity and the dynamics of energy prices. Energy Policy, 33, $2244-$ 2255.

[11] Gómez, V. and Maravall, A. (1996): Programs TRAMO and SEATS, instruction for user (Beta Version: september 1996), Banco de Espana Working Papers 9628, Banco de España.

[12] Granger, C.W.J. (1969): Investigating causal relations by econometric models and cross-spectral methods. Econometrica, 37, 424-438. 
[13] Johansen, S. and Juselius K. (1990): Maximum likelihood estimation and inference on cointegration, with applications for demand for money. Oxford Bulletin of Economics and Statistics, 52, 169 - 210.

[14] Kirchgässner, G. and Wolters, J. (2007): Introduction to Modern Time Series Analysis. Berlin: Springer-Verlag.

[15] Klier, T. and Rubenstein J. (2011): What role did regional policy play in addressing the US auto industry crisis? International Journal of Automotive Technology and Management, 11, 189 - 204.

[16] Lütkepohl, H. (2005): New Introduction to Multiple Time Series Analysis. Berlin: Springer-Verlag.

[17] Lütkepohl, H. and Krätzig, M. (2004): Applied Time Series Econometrics Edited. Cambridge: Cambridge University Press.

[18] Maddala, G.S. (1997): Recent Developments In Dynamic Econometric Modelling: A Personal Viewpoint. Annual Meeting of the Political Methodology Group, Columbus, Ohio July 24-27, 1997.

[19] Montgomery, D.C., Johnson L.A., and Gardner J.S. (1990): Forecasting and Time Series Analysis. New York: McGraw-Hill.

[20] Narayan, P., Narayan S., and Prasad A. (2008): A structural Var analysis of electricity consumption and real GDP: Evidence from G7 countries. Energy Policy, 36, 2765-2769.

[21] Pagan, A.R. (1989): 20 years after: Econometrics 1966-1986. In B. Cornet and H. Tulkens (Eds): Contributions to Operations Research and Econometrics, The XXth Anniversary of CORE. Cambridge: MIT Press.

[22] Robalo, P.B. and Salvado, J.C. (2008): Oil price shocks and the Portuguese economy since the 1970s. Working Paper Series, Universidade Nova de Lisboa, Faculdade de Economia.

[23] Tiao, G.C. (1985): Autoregressive moving average models, intervention problems and outlier detection in time series. In Hannan E.J., Krishnaiah P.R., and Rao M.M. (Eds): Handbook of Statistics, 5.

[24] Tsay, R.S. (1986): Time series model specification in the presence of outliers. Journal of the American Statistical Association, 81, 132. 